\title{
POTENCIAL DA UTILIZAÇÃO DE FRUTAS TÍPICAS DO SEMIÁRIDO POTIGUAR COMO FONTE DE SUBSTRATO NA FERMENTAÇÃO ALCOÓLICA
}

\author{
M. S. L. BENEVIDES ${ }^{1}$, M. V. L. O. $\operatorname{SOARES}^{1}$,A. A. L. ARAUJO ${ }^{1}$, R. D. VALENÇA ${ }^{1}$, A. D. T. \\ PINHEIRO ${ }^{1}$.
}

${ }^{1}$ Universidade Federal Rural do Semi-Árido, Departamento de Agrotecnologia e Ciências Sociais Email: alvarodaniel@ufersa.edu.br

\begin{abstract}
RESUMO - O Rio Grande do Norte destaca-se pela fruticultura irrigada e por ser um dos polos agrícolas mais variados do Nordeste brasileiro, sendo o melão, o caju, a banana, a manga, a melancia e a uva as principais frutas produzidas nessa região. Nesse contexto, estudou-se a influência do processamento inicial do melão de três diferentes formas, utilizando como meio de cultura: o suco extraído da polpa do melão, da polpa mais entrecasca e do fruto completo (polpa + entrecasca + casca). As fermentações foram realizadas em incubadora tiposhaker a $30{ }^{\circ} \mathrm{C}$ e rotação de $150 \mathrm{rpm}$ por um período de 10 horas. Ao utilizar-se apenas o suco da polpa do melão como substrato, foi observado o melhor rendimento $92 \%$ e o melhor crescimento celular quando comparado com o suco da polpa do melão com a entrecasca que obteve uma eficiência de $63 \%$ e com o suco da polpa do melão com a casca $77 \%$.
\end{abstract}

\section{INTRODUÇÃO}

O Nordeste brasileiro é favorecido a exploração da fruticultura tropical irrigada. De acordo com esse cenário nordestino, o Rio Grande do Norte tem aumentado sua produção na fruticultura irrigada, sendo, hoje, o maior produtor e exportador nacional de melão e carro-chefe na comercialização de frutas para o exterior, como: banana, manga, caju, mamão, melancia e acerola (ARAUJO \& CAMPOS, 2011).

No final do século XIX, no nordeste brasileiro, destacaram-se as ações governamentais para a modernização da agricultura consistindo no incentivo a irrigação nas áreas semiáridas, dando continuidade a velha politica das águas. O sucesso do programa exigia a construção de obras de infraestrutura hídrica (açudes, poços, barragens) e de irrigação. Então, a partir desse esforço essa região passou a ocupar um lugar de destaque no setor de fruticultura irrigada e, a maior região produtora de melão no país atualmente localiza-se no polo Açu/Mossoró, no Rio Grande do Norte (SOUZA, 2005).

O polo Açu/Mossoró localiza-se na região oeste do Rio Grande do Norte, sendo o mesmo dividido em duas subzonas: a de Açu e a de Mossoró, que se diferenciam quanto à forma de captação de água para irrigação.Na subzona de Açu, a irrigação é feita através de canais que captam água dos rios Pataxó, Piranhas e da Barragem Armando Ribeiro Gonçalves, já a subzona de Mossoró, a captação da água é feita principalmente através de poços artesianos. Esse polo compreende os municípios potiguares de Mossoró, Açu, Baraúna, Carnaubais, Upanema, 
Ipanguaçu, Alto do Rodrigues, Afonso Bezerra, Pendências e Serra do Mel. E caracteriza-se pela produção irrigada de frutas, predominando as culturas de melão, melancia, banana e caju (HORTIFRUTI BRASIL, 2006).

Quanto à fermentação alcóolica, sabe-se que a mesma consiste na transformação de carboidratos em etanol e gás carbônico através do metabolismo anaeróbio, podendo a mesma gerar outras substâncias como glicerol e ácido acético em menores quantidades. Os substratos utilizados na fermentação alcoólica são altamente variáveis e podem ser constituídos por produtos de açúcar, tais como o caldo de cana-de-açúcar, raiz de beterraba, mel, melaço e frutas ou de matérias amiláceas, como grãos de amido, raízes tubérculos e outros (ALENCAR et al., 2009).

Desta maneira, o presente trabalho teve como objetivo avaliar a produção de etanol por fermentação do suco de melão proveniente doprocessamento da polpa do melão, da polpa e da entrecasca e polpa juntamente com a casca.

\section{MATERIAIS E MÉTODOS}

\subsection{Obtenção do suco de melão}

A produção de etanol foi avaliada a partir de três sucos de melão (suco da polpa do melão, da polpa do melão com a entrecasca e da polpa com a casca). Esses sucos não clarificados foram obtidos a partir do melão amarelo e foram fermentados utilizando a levedura Saccharomycescerevisiae. O desempenho do substrato no processo de fermentação dos sucos foi avaliado através da produção de etanol, consumo de substrato e pelo rendimento final de etanol.

Inicialmente, os melões foram lavados em água e álcool etílico 70\%. Em seguida, o melão foi cortado em cubos, os quais foram triturados para a obtenção do suco. Seu pH foi ajustado com ácido sulfúrico P.A. para 4,5 e sua esterilização se deu em autoclave a $110{ }^{\circ} \mathrm{C}$ por 10 minutos.

\subsection{Microrganismo}

O microrganismo utilizado como substrato para fermentação alcoólica foi à levedura comercial Saccharomycescerevisiae. Desta forma pesaram-se $3 \mathrm{~g}$ desses microrganismos e os mesmos foram colocados dentro deerlenmeyers de $500 \mathrm{~mL}$ para crescer em 1,5 L de meio sintético (glicose+frutose). Posteriormente foram colocados em uma incubadora tiposhaker a uma temperatura de $30^{\circ} \mathrm{C}$ e $150 \mathrm{rpm}$ por um período de 24 horas.

\subsection{Fermentação}

A fermentação alcoólica ocorreu em frascos de erlenmeyer de $500 \mathrm{~mL}$, utilizando $250 \mathrm{~mL}$ de suco de melão como meio de cultura e 5 g. $\mathrm{L}^{-1}$ de concentração da levedura Saccharomycescerevisiae, conduzidas em shaker (Tecnal - TE 420) sob agitação de $150 \mathrm{rpm}$ por um período de 10 horas e $30{ }^{\circ} \mathrm{C}$. Amostras foram retiradas em intervalos de tempo pré-definidos para serem analisadas. 


\subsection{Métodos analíticos}

Concentração celular: Para mensurar a concentração de biomassa, fez-se uso da densidade óptica (D.O) a $410 \mathrm{~nm}$ com auxílio de um espectrofotômetro. Esse método é baseado na medida da turvação de uma solução em função da quantidade de células em suspensão, sendo simples e rápida a sua execução.

Concentração de substrato e produto: Para mensurar as concentrações de substrato e produtos, utilizou-se cromatógrafo líquido de alta eficiência - CLAE (Waters, Milford, MA, EUA) equipado com um detector de índice de refração Waters 2414 e com uma coluna Aminex HPX-87H (Bio-Rad, Hercules, CA, EUA). Ácido sulfúrico $5 \mathrm{mmol} . \mathrm{L}^{-1}$ foi usado como fase móvel (eluente) na vazão de $0,5 \mathrm{~mL} \cdot \mathrm{min}^{-1}$ a $65^{\circ} \mathrm{C}$, sendo o volume de injeção das amostras de $20 \mu \mathrm{L}$.

Cálculo dos rendimentos e parâmetros cinéticos: A partir dos ensaios experimentais, obtiveram-se os dados necessários (concentração de biomassa, substrato, produto) para determinação dos parâmetros cinéticos da fermentação alcoólica, tais como velocidade específica de crescimento $\left(\mu_{\text {máx }}\right)$, conversão de célula em produto $\left(\mathrm{Y}_{\mathrm{p} / \mathrm{x}}\right)$, conversão de substrato em célula $\left(\mathrm{Y}_{\mathrm{x} / \mathrm{s}}\right)$, conversão, eficiência e produtividade.

\section{RESULTADOS}

A influência do processamento inicial do melão na produção de etanol foi avaliada a partir do consumo do substrato, da formação de etanol e do crescimento celular, sendo o resultado mostrado na Figura 1.Analisando a Figura 1, observa-se que ao utilizar o suco da polpa do melão como substrato, verifica-se que após $10 \mathrm{~h}$ de fermentação ocorreu um maior crescimento celular 12,20 g.L L $^{-1}$.Já no suco do melão com a casca, todo substrato foi consumido após $6 \mathrm{~h}$ de fermentação. A maior produção de etanol $\left(54,34 \mathrm{~g} \cdot \mathrm{L}^{-1}\right)$ ocorreu quando utilizou-se o suco da polpa do melão como substrato, sendo a menor $\left(22,97\right.$ g. $\left.\mathrm{L}^{-1}\right)$ obtida no suco da polpa do melão com a casca.

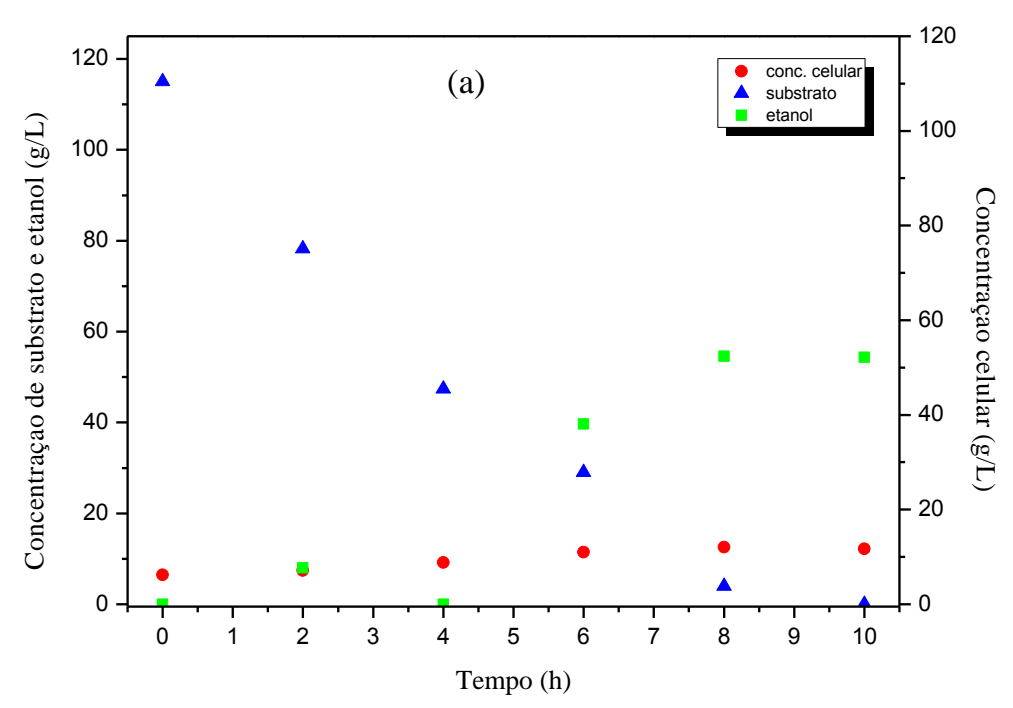



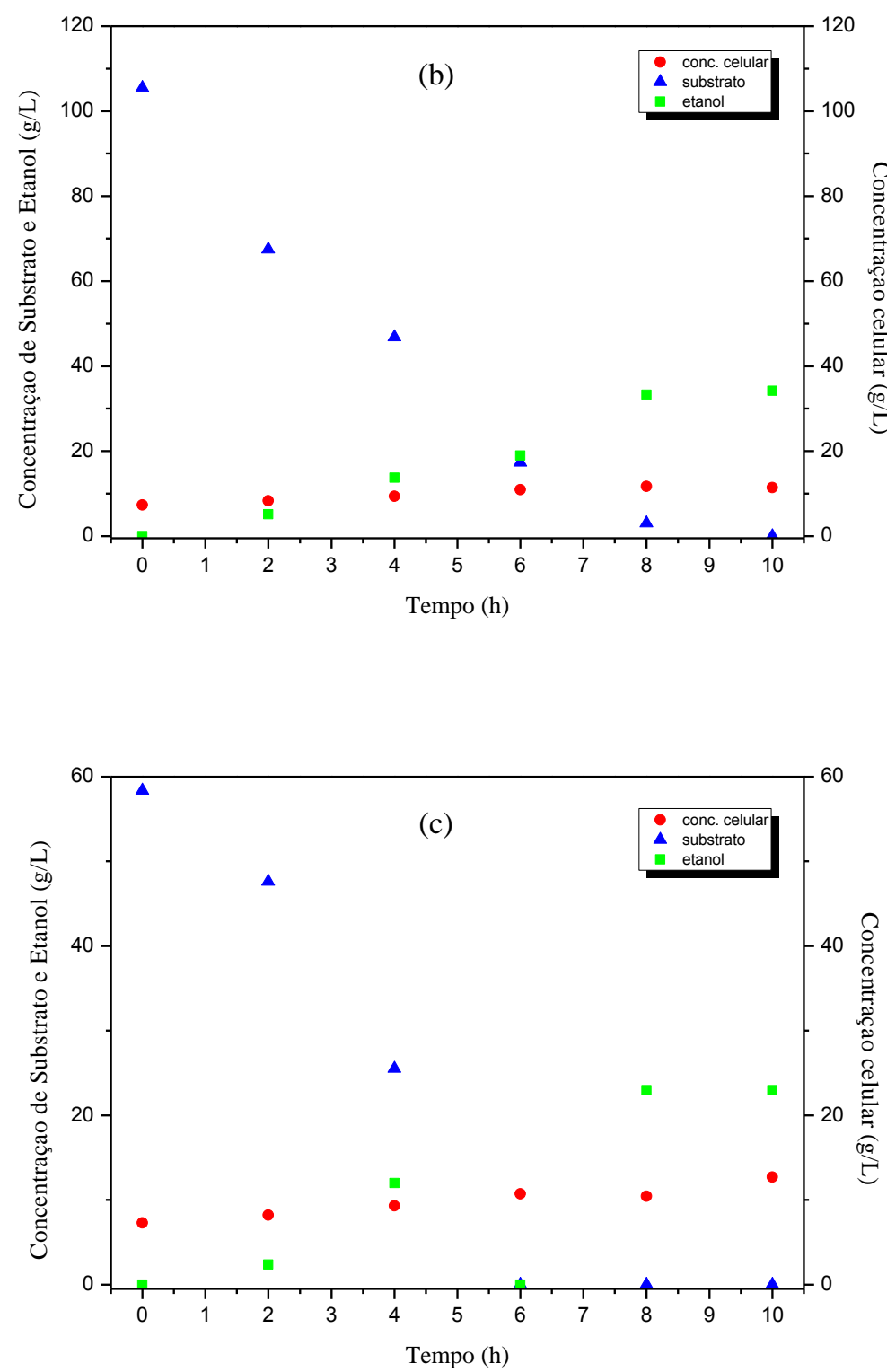

Figura 1. Efeito do processamento do melão na cinética do processo fermentativo. (a) suco da polpa; (b) suco da polpa com a entrecasca; (c) suco da polpa com a casca.

Além da análise gráfica do perfil do processo fermentativo, avaliou-se a influência dos sucos do melão nos seguintes parâmetros cinéticos: máxima velocidade especifica de crescimento ( $\left.\mu_{\text {máx }}\right)$, conversão de célula em produto $\left(\mathrm{Y}_{\mathrm{p} / \mathrm{x}}\right)$, conversão de substrato em célula $\left(\mathrm{Y}_{\mathrm{x} / \mathrm{s}}\right)$, conversão, eficiência e produtividade. Os valores obtidos para os parâmetros citados anteriormente encontram-se na Tabela 1, para o suco da polpa do melão, da polpa mais a entrecasca e da polpa mais a casca. 
Tabela 1 - Parâmetros cinéticos obtidos para a levedura Saccharomycescerevisae para os diferentes tipos de substratos na fermentação alcóolica do suco de melão.

\begin{tabular}{cccc}
\hline \multirow{2}{*}{ Parâmetros cinéticos } & \multicolumn{3}{c}{ Substratos } \\
\cline { 2 - 4 } & Polpa de melão & Polpa + entrecasca & Polpa + casca \\
\hline$\mu_{\text {máx }}\left(\mathrm{h}^{-1}\right)$ & 0,0639 & 0,0441 & 0,0555 \\
$\mathrm{Y}_{\mathrm{x} / \mathrm{s}}\left(\mathrm{g} \cdot \mathrm{g}^{-1}\right)$ & 0,05 & 0,04 & 0,09 \\
$\mathrm{Y}_{\mathrm{p} / \mathrm{x}}\left(\mathrm{g} \cdot \mathrm{g}^{-1}\right)$ & 9,43 & 8,42 & 4,25 \\
$\mathrm{Y}_{\mathrm{p} / \mathrm{s}}\left(\mathrm{g} \cdot \mathrm{g}^{-1}\right)$ & 0,47 & 0,32 & 0,39 \\
$\eta(\%)$ & 92,446 & 63,375 & 77,001 \\
$\mathrm{Q}_{\mathrm{p}}\left(\mathrm{g} \cdot \mathrm{L}^{-1} \cdot \mathrm{h}^{-1}\right)$ & 6,821 & 3,416 & 2,297 \\
\end{tabular}

De acordo com a Tabela 1, observa-se que a máxima velocidade específica de crescimento $\left(\mu_{\text {máx }}\right)$ apresentou uma diminuição entre o suco da polpa do melão $\left(0,0639 \mathrm{~g} \cdot \mathrm{g}^{-1}\right)$, a polpa com a entrecasca $\left(0,0441 \mathrm{~g} . \mathrm{g}^{-1}\right)$ e a polpa com a casca $\left(0,0555 \mathrm{~g} \cdot \mathrm{g}^{-1}\right)$, isso ocorre devido à presença de taninos (fenóis presentes no fruto verde de muitas plantas e que atuam como instrumento de defesa) na casca do melão. Os parâmetros de conversão de substrato em célula $\left(\mathrm{Y}_{\mathrm{x} / \mathrm{s}}\right)$ e célula em produto $\left(\mathrm{Y}_{\mathrm{p} / \mathrm{x}}\right)$ apresentaram comportamentos distintos. Apresenta um aumento de $\mathrm{Y}_{\mathrm{x} / \mathrm{s}}$, que relaciona a quantidade de biomassa produzida e a quantidade de substrato consumida, sendoque quanto menor seu valor melhor, a polpa com a entrecasca $\left(0,04 \mathrm{~g}_{\mathrm{g}} \mathrm{g}^{-1}\right)$, e o $\mathrm{Y}_{\mathrm{p} / \mathrm{x}}$, que relaciona o produto formado por biomassa consumida, apresenta valores decrescentes onde quanto maior seu valor melhor, a polpa do melão $\left(9,43 \mathrm{~g} \cdot \mathrm{g}^{-1}\right)$. Na conversão de $\mathrm{Y}_{\mathrm{p} / \mathrm{s}}$, que relaciona o produto formado pelo substrato, o da polpa de melão possui o maior valor $\left(0,47 \mathrm{~g} \cdot \mathrm{g}^{-1}\right)$.Em relação ao rendimento $(\eta)$, possui um maior valor para o suco da polpa do melão $(92,45 \%)$, seguido do suco da polpa do melão com a casca $(77 \%)$ e assumindo um valor inferior $(63,37 \%)$ para o suco da polpa do melão com a entrecasca. Observando também a produtividade, que é a concentração máxima de etanol obtida pelo tempo que levou para o obtenção do mesmo, verifica-se uma diminuição entre os substratos, sendo o melhor resultado a da polpa do suco de melão $\left(6,821\right.$ g.. $\mathrm{L}^{-}$ $\left.{ }^{1} \cdot \mathrm{h}^{-1}\right)$

\section{CONCLUSÃO}

De acordo com os resultados obtidos na avaliação dos sucos de melão como substrato, observou-se que o suco da polpa do melão é bastante influente no rendimento do processo de fermentação alcoólica. Os resultados mostraram cinéticas diferentes para a fermentação do suco da polpa do melão, da polpa mais a entrecasca e da polpa mais a casca. A influência dos sucos do melão também foi avaliada calculando-se os parâmetros de máxima velocidade especifica de crescimento $\left(\mu_{\text {máx }}\right)$, da conversão de célula em produto $\left(\mathrm{Y}_{\mathrm{p} / \mathrm{x}}\right)$, conversão de substrato em célula $\left(\mathrm{Y}_{\mathrm{x} / \mathrm{s}}\right)$, conversão de substrato em produto $\left(\mathrm{Y}_{\mathrm{p} / \mathrm{s}}\right)$, conversão, eficiência e produtividade, os melhores resultados obtidos na conversão de substrato em produto e no rendimento da fermentação foi de 0,47 g.L $L^{-1}$ e $92,45 \%$, respectivamente.Portanto, constatou-se que o suco da polpa do melão apresenta todas as características necessárias para a produção do etanol.

\section{REFERÊNCIAS}


ALENCAR, E. M. B.; SOUZA-MOTTA, C.M.; WALTER, B. S.; SANTOS, R. M. P.; MARQUES, O. M.; QUEIROZ, L. A. FermentationcapacityofSaccharomycescerevisiaecultures. Braz. Arch. Biol.Technol. v. 52, n. 4, p. 819-824, July/Aug., 2009.

Hortifruti Brasil. CEPEA-USP/ESALQ.n.44. p. 1-28, 2006.

NACHREINER, M. L.; BOTEON, M.; DE PAULA, T.S. Sistema agroindustrial do melão: Mossoró versus Juazeiro. São Paulo: USP, 2002.

OLIVEIRA, L. G.; MANTOVANI, S. M. Transformações biológicas: contribuições e perspectivas. Quim. Nova, v. 32, n. 3, p. 742-756, 2009.

SCHIMIDELL, W.; LIMA, U. A.; AQUARONE, E.; BORZANI, W.Biotecnologia Industrial EngenhariaBioquímica.v. 2, São Paulo: Blucher, 2001.

SOUZA, F. C. S. Potencialidades e (in)sustentabilidade no semiárido potiguar. Natal: Editora do CEFET-RN, 2005. 